\title{
Abundance and distribution of planktonic coral larvae in Kaneohe Bay, Oahu, Hawaii
}

\author{
Gregor Hodgson
}

East-West Center and Department of Zoology, University of Hawaii, Honolulu, Hawaii 96822, USA

\begin{abstract}
A plankton sampling program was designed for the capture of coral planulae. More than 250 surface tows were made with a small, fine-mesh net along 5 transects established near the southeast fringing reef of Coconut Island, Oahu, Hawaii. Time between collection and sorting was minimized, and low temperature storage was employed in lieu of chemical fixation to prevent decomposition of the planulae prior to identification. More than $20,000 \mathrm{cnidarian} \mathrm{larvae} \mathrm{were} \mathrm{collected}$ and sorted, of which $90 \%$ were scleractinian planulae. Twelve different types of cnidarian larvae were recognized. Six were identified as the planulae of the corals Pocillopora damicornis, Porites compressa, Montipora verrucosa, M. dilitata, Cyphastrea ocellina and Fungia scutaria. Two appear to be the zoanthina larvae of the zoanthids Palythoa vestitus and Zoanthus pacificus. Peak recovery of planulae generally occurred 3 to $7 \mathrm{~d}$ after onset of spawning or planulation. Limited data indicate that some coral planulae may undertake diurnal migration, residing near the surface at night and moving to several meters depth during the day. The potential for the export of large numbers of coral planulae from Kaneohe Bay is considered high, but whether this export is significant to recruitment on reefs outside the bay remains to be determined.
\end{abstract}

\section{INTRODUCTION}

An increasing amount of work has documented the timing and mode of coral reproduction, the recruitment of juveniles on artificial and natural substrates and the behavior of coral planulae in the laboratory (see reviews by Highsmith 1982 and Fadlallah 1983). The calorimetric work of Richmond (1982) has demonstrated that the century-old assumption that coral planulae are capable of dispersing over long distances (Semper 1881, Vaughan 1907), is at least energetically justified in certain species. Despite these advances, little effort has been made to measure the abundance and distribution of coral planulae in the field.

Since the early 1800's when plankton nets were first used (Fraser 1979), dozens of reports have been published concerning tropical plankton in the open ocean and near shore. Out of 44 such reports available to the author, only 15 recorded larval cnidarians. Although several of these studies were devoted to descriptions of the zooplankton found living near coral reefs, only 10

Contribution No. 703 of the Hawaii Institute of Marine Biology, USA have reported coral planulae (Vaughan 1910, Stephenson 1931, Russell \& Colman 1934, Kawaguti 1940, Harrigan 1972, Yamaguchi 1972, Clutter 1973, Harrison et al. 1984, Bull 1984 in press).

Although Vaughan (1910) stated that 'Madreporarian planulae' were common in the plankton tows off the Dry Tortugas, researchers since then who have tried to obtain coral planulae using nets have remarked on their scarcity. For example, Yamaguchi (1972) searched through 60 plankton hauls taken near a reef in Palau and recovered only a single specimen.

Perhaps more surprising is the complete lack of planulae caught by the specialized demersal plankton traps of Alldredge \& King (1977), Porter \& Porter (1977), Porter et al. (1977), Birkeland \& Smalley (1982) and Walter et al. (1982). In contrast, Kitalong (unpubl.) reports that hundreds of coral planulae occasionally were caught in her demersal traps. These traps were also placed directly over the reef substrate.

The purpose of the present paper is to identify and quantify the coral planulae found near a coral reef in Hawaii. Information on the residence time of planulae in the plankton and their horizontal distribution near the surface is also presented. 


\section{MATERIALS AND METHODS}

Plankton tows. The primary study area was located at the southeast fringing reef of Coconut Island, Kaneohe Bay, Oahu, Hawaii (Fig. 1). This reef portion was chosen because of the abundance of Pocillopora damicornis colonies. This species is known to produce abundant planulae following a lunar cycle (Richmond \& Jokiel 1984).

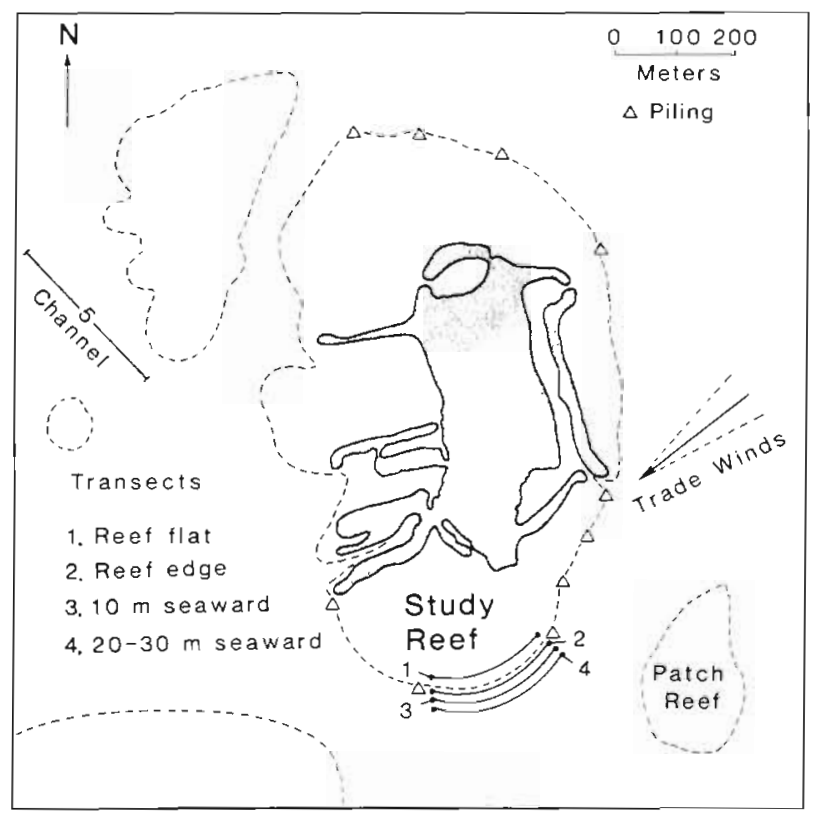

Fig. 1. Map of Coconut Island (stippled) showing the location of Transects 1 to 5 in relation to study reef and adjacent patch reefs (broken lines)

Four plankton tow transects were established parallel to the reef front. Transect 1 was located between the zone of active coral growth on the outer reef flat and the sandy inner reef flat and was $10 \mathrm{~m}$ from the seaward reef edge. Transect 2 was located directly over the seaward reef edge. Transects 3 and 4 were established 10 and $20 \mathrm{~m}$ seaward of the reef edge respectively. Transect 5 was located in an outflow channel of the Kaneohe Bay southeast basin, several hundred meters northwest of the main study area. The beginning and end points of the transects were marked relative to pilings along the reef edge.

All plankton tows were made using a $30 \mathrm{~cm}$ diameter, $104 \mu \mathrm{m}$ mesh, nylon net fitted with a TSK flow meter. To enable sampling over the reef flat, the net's mouth-ring was suspended beneath a flat $(35 \times 30 \times 5 \mathrm{~cm})$ styrofoam float. The net was fastened below the float so that the top of the mouth was at the level of the water surface. A smaller float was tied to the cod end to prevent the net from dragging across the bottom. Plankton tows could be taken over the reef flat whenever the water depth exceeded about $35 \mathrm{~cm}$. To maintain continuity of the sampling regimen, all plankton tows were carried out with the floats in place. In this way, only the top $30 \mathrm{~cm}$ of water was filtered by the net.

The net was towed behind a skiff at an average speed of 2 to 3 knots for all tows except those taken when there was insufficient water over the reef flat. At these times the net was towed by hand while walking over the reef flat along the transect. Separate calibrations were made for the flow meter at the boat tow and the walking speeds. A sample run consisted of one pass along a given transect. This would usually take 3 to $4 \mathrm{~min}$ and filtered an average of $17.5 \mathrm{~m}^{3}$ of water. At the end of a sample run the net was washed down and the plankton collected in a 6 ounce $(177 \mathrm{ml})$ cod end bottle.

Generally, sampling was carried out every other day from 22 June through 1 August, 1983. An exception was Transect 2 (20 $\mathrm{m}$ seaward) which was not sampled until mid-July. During June, sampling was carried out primarily just after low tides since Pocillopora damicornis colonies held in the laboratory showed peak planulation during low tide (Holloran \& Witteman in press). After June, samples were taken at a variety of times and tidal stages.

One $24 \mathrm{~h}$ and one $12 \mathrm{~h}$ contiguous sample series were also carried out. For the $24 \mathrm{~h}$ series (29 to 30 June), 4 sample runs were taken every $4 \mathrm{~h}$ along the seaward reef edge transect. The sampling regimen of the $12 \mathrm{~h}$ series entailed 3 double sample runs (up and back) along the seaward reef edge every $2 \mathrm{~h}$ from noon to midnight (29 July). The 12 and $24 \mathrm{~h}$ studies were designed to clarify the diumal pattern of abundance of Pocillopora damicornis and Porites compressa planulae.

Processing of samples. In the field, the concentrated plankton samples were decanted into $280 \mathrm{ml}$ glass bottles and cooled over ice to about $10^{\circ} \mathrm{C}$ in a 201 insulated plastic container. The most important benefit of this procedure was that most coral planulae survived for 2 to $3 \mathrm{~h}$ in this cool, presumably low-oxygen, environment long after the other plankton had died. The majority of the planulae were observed with the naked eye swimming near the surface. From there they were collected with a pipette for settling experiments. The remaining plankton was then examined to find the injured or dead planulae which generally sank to the bottom (usually about one third of the total number). Few planulae were found in the middle layers of clear water above the settled mass of plankton. All samples were counted with the aid of a dissecting microscope within $3 \mathrm{~h}$ of collection. No formalin or other fixatives were added. All planulae were counted individually in a sorting dish unless their abundance was greater than 200. In this case, subsampling was carried out for the 
abundant species, with the less abundant species counted individually from the total sample.

Identification of planulae. The distinct planulae of Pocillopora damicornis have been described in detail by Edmondson (1929), Harrigan (1972) and Vandermeulen (1974). Although the planulae of $P$. damicornis, Type B (Richmond \& Jokiel 1984) may be smaller on the average than those of Type $Y$, there is no way to positively assign a given individual planula taken in a plankton tow to its proper type because of the large overlap in their size ranges. Therefore all $P$. damicornis planulae were lumped into one group for the present analysis. Cyphastrea ocellina planulae also have unique features (Edmondson 1929). The planulae of both species are easily distinguished from those of other species and identified. In contrast, the larvae of Porites compressa, Montipora verrucosa and $M$. dilitata are plain and difficult to tell apart. Larvae of these species and of Fungia scutaria were identified by comparing them with larvae of known origin collected in the laboratory or in the field. Large, well-rounded eggs were considered to have been fertilized and were counted as planulae. $P$. compressa and $M$. verrucosa larvae collected from plankton tows were also allowed to settle and grow in aquaria until their identification could be confirmed based on skeletal morphology.

Data analysis. The standard deviations of sample means were too large, with the exception of the diurnal cycle data, to make meaningful statistical comparisons between transects. Individual data points were not regarded as absolute values. Rather, these preliminary results were examined to discover trends in planula abundance over time and distance. In many cases the number of planulae recovered per $\mathrm{m}^{3}$ was very low. In order to avoid the use of small fractions of planulae, all values in this study were normalized to $100 \mathrm{~m}^{3}$ of seawater filtered.

Water circulation. Water circulation around Coconut Island was studied using drogues and fluoroscene dye. On 21 June, 1 July and 6 August the drogues and dye were released from 17 locations, and their drift paths and speeds recorded during the incoming and outgoing tides.

\section{RESULTS}

\section{Weather and water circulation}

During the study period water temperature off the reef edge was $26.4^{\circ} \mathrm{C}\left( \pm 0.5 \mathrm{C}^{\circ}\right)$. The normal northeast tradewinds for this period blew at an average velocity of $15.6 \pm 9.5 \mathrm{kph}$. The average direction was from $50^{\circ}$ east of north with a range of $10^{\circ}$ (National Weather Service). Wind strength has a profound effect on water circulation in the bay (Bathen 1968). This effect is
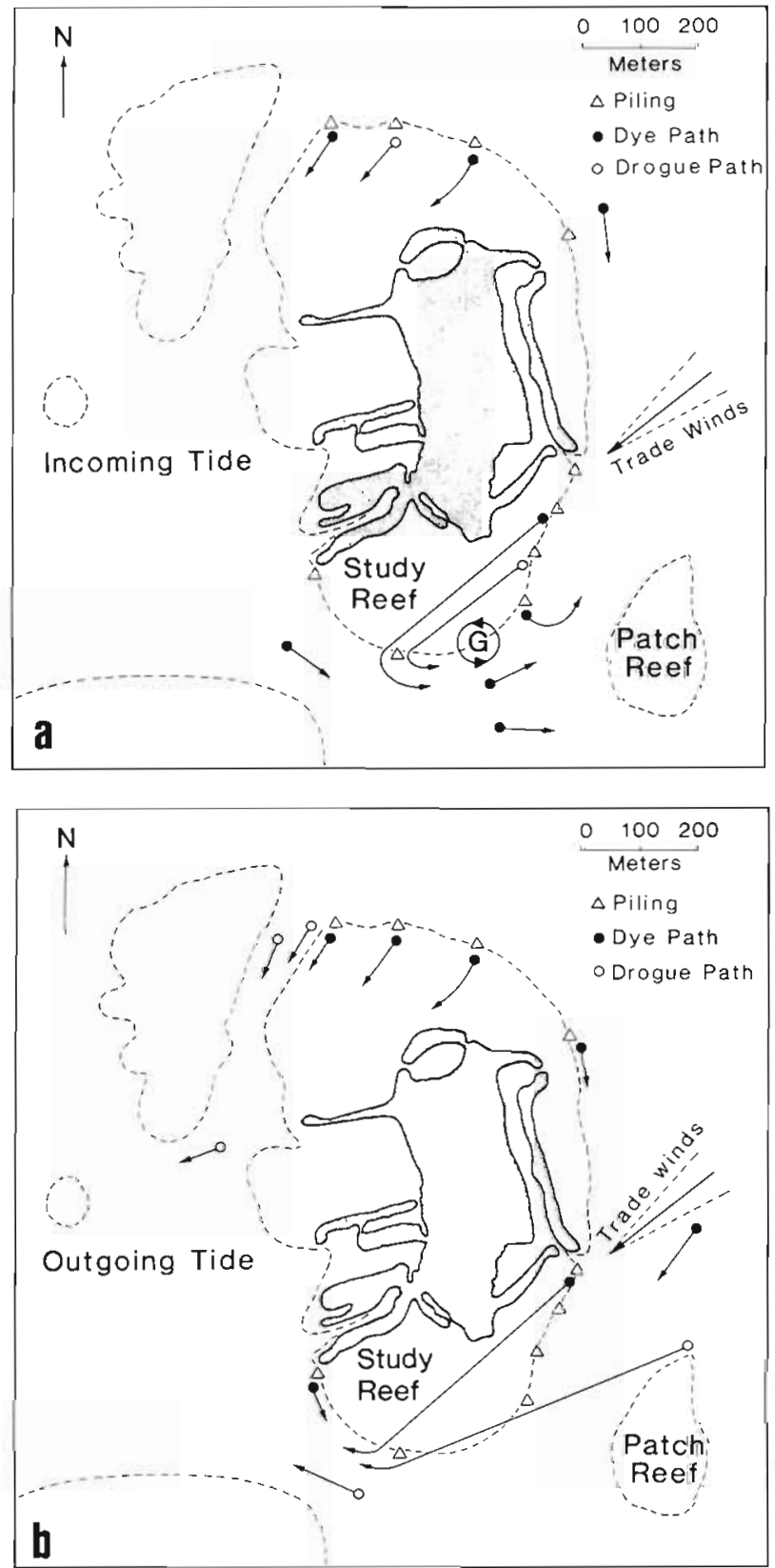

Fig. 2. Map of Coconut Island (stippled). (a) Current patterns (arrows) near the study reef (broken line) during the incoming tide; note that the gyre $(G)$ exists during tradewind conditions. (b) Current patterns during outgoing tide

especially marked in shallow areas such as reef flats. There the wind can create strong currents which may run in opposite directions to the tidal currents.

Fig. 2a and $b$ show the drift paths of the drogues and dye released during the incoming and outgoing tides. A $16 \mathrm{kph}$ wind generated a current over the study reef along Transect 1 ranging between 7 and $10 \mathrm{~cm} \mathrm{~s}^{-1}$ when the water depth was $70 \mathrm{~cm}$. A gyre exists near the south end of the study reef during an incoming tide 
Table 1. Characteristics of the cnidarian larvae caught in plankton tows in Kaneohe Bay. With the exception of Semper's and Cerianthus sp. larvae, all larvae can change their body form to a club, barrel, or piriform shape and a round ball. The shapes and size ranges listed refer to those assumed while the larvae swim directionally. Identifications were made via literature (L), direct observation of planulation (P), or of spawning (S), and examination of polyps and skeletons grown (G) from larvae of known origin

\begin{tabular}{|c|c|c|c|c|c|c|}
\hline Species/type & $\begin{array}{l}\text { Length } \\
(\mu \mathrm{m})\end{array}$ & $\begin{array}{l}\text { Width } \\
(\mu \mathrm{m})\end{array}$ & Color & Shape & $\begin{array}{l}\text { Swim- } \\
\text { ming } \\
\text { speed } \\
\left(\mathrm{mm} \mathrm{s}^{-1}\right)\end{array}$ & $\begin{array}{l}\text { Identifi- } \\
\text { cation }\end{array}$ \\
\hline Anthopleura nigrescens (?) & $200-230$ & $130-170$ & Transparent ectoderm, red center & Piriform & $2-3$ & $\mathrm{~L}$ \\
\hline Cerianthus sp. (?) & 300 & 300 & $\begin{array}{l}\text { White, beige, orange, dark circle } \\
\text { around oral ciliary tuft }\end{array}$ & Bullet & $5-8$ & $\mathrm{~L}$ \\
\hline Cyphastrea ocellina & $750-950$ & $400-600$ & $\begin{array}{l}\text { Beige endoderm, pearly white ecto- } \\
\text { derm with tiny wart-like projections }\end{array}$ & Piriform & $2-3$ & $\mathrm{~L}, \mathrm{G}$ \\
\hline Fungia scutaria & $90-120$ & $50-70$ & White & Piriform & $2-3$ & $\mathrm{~L}, \mathrm{~S}$ \\
\hline Montipora dilitata & $250-300$ & $110-175$ & Beige & Piriform & $1-2$ & $S$ \\
\hline Montipora verrucosa & $250-300$ & $110-175$ & Beige & Piriform & $1-2$ & $S, G$ \\
\hline $\begin{array}{l}\text { Pocillopora damicornis } \\
\text { (Type B) } \\
\text { (Type Y) }\end{array}$ & $\begin{array}{l}750-1200 \\
750-2000\end{array}$ & $\begin{array}{l}400-600 \\
500-1000\end{array}$ & $\begin{array}{l}\text { White, longitudinal } \\
\text { brown stripes }\end{array}$ & Piriform & $2-3$ & $L, P, G$ \\
\hline Porites compressa & $\begin{array}{l}245-300 \\
245-300\end{array}$ & $200-245$ & Beige & Piriform & $1-2$ & S, G \\
\hline $\begin{array}{l}\text { Semper's } \\
\text { (Type 1) } \\
\text { (Type 2) }\end{array}$ & $\begin{array}{l}180-220 \\
190-230\end{array}$ & $\begin{array}{l}170-210 \\
150-170\end{array}$ & $\begin{array}{l}\text { Greenish brown } \\
\text { Beige }\end{array}$ & $\begin{array}{l}\text { Piriform, } \\
\text { central } \\
\text { constriction }\end{array}$ & $<1$ & L \\
\hline
\end{tabular}

(Fig. 2a). During an outgoing tide, dye and drogues released at the surface near the north end of the patchreef located just over $100 \mathrm{~m}$ east of the study reef, were swept directly onto the study reef within 1 to $2 \mathrm{~h}$ (Fig. $2 b)$. They crossed the study reef within $30 \mathrm{~min}$ and were then swept into the outflow channel south of the island.

Kaneohe Bay has a modified semi-diurnal tidal cycle which had a range of $1 \mathrm{~m}$ during the study period. Full moon occurred on 26 June and 25 July.

\section{Types and abundance of planulae}

Well over 20,000 cnidarian planulae were collected and counted over the course of the study; the majority of these were scleractinian planulae. Twelve types of larvae were recognized and are described in Table 1. Two were tentatively identified as zoanthids and 6 were positively identified to the species level as coral planulae. The 6 included: Pocillopora damicornis, Porites compressa, Montipora verrucosa, $M$. dilitata, Cyphastrea ocellina, and Fungia scutaria. The remaining types of planulae remain unidentified.

The daily mean number of Pocillopora damicornis planulae collected along each transect is plotted in Fig. 3. The major peak in the catch occurred between
27 and 29 June, reaching over 100 planulae $100 \mathrm{~m}^{-3}$. There were 3 smaller peaks around 23 June, 6 July and 18 July, with the last peak subsiding slowly through 4 August when the study ended.

Porites compressa colonies were observed spawning eggs in the field and in the laboratory at approximately 2 wk intervals (at new and full moon) beginning on 26 June. The water surface of the channel at the south end of Coconut Island (Fig. 1) was covered with beige $P$. compressa eggs and planulae for $2 \mathrm{~d}$ during each spawning period.

The daily mean number of Porites compressa planulae collected along each transect was plotted in Fig. 4. There were 3 abundance peaks that followed the fortnightly spawning periods. Maximum abundance reached 1390 planulae $100 \mathrm{~m}^{-3}$.

In the laboratory and in the field, Montipora verrucosa colonies spawned the majority of their egg-sperm packets between 10 and 12 July 1983 (new moon) at approximately $2100 \mathrm{~h}$. Small numbers of remaining egg-sperm packets were released on the following 3 nights. Details of the spawning of this species are given by Heyward (in press). Egg-sperm packets, eggs, and later planulae, were collected in plankton tows between 10 July and 22 July, with a peak on 16 July which reached 16,000 planulae $100 \mathrm{~m}^{-3}$ (Fig. 5).

Montipora dilitata colonies were observed to begin 
Fig. 3. Pocillopora damicornis. Daily mean number of planulae (Types Y plus B) recovered per $100 \mathrm{~m}^{3}$ seawater, Each data point represents mean catch from 3 tows along the specified transect. Separate planulation periods of Type $Y$ and $\mathrm{B}$ colonies held in the laboratory (Holloran \& Witteman in press) are marked with dotted lines. Transect 2 data points are connected. Tide stages: $E=$ ebb (outgoing), $F=$ flow (incoming),

$$
\mathrm{H}=\text { high }
$$

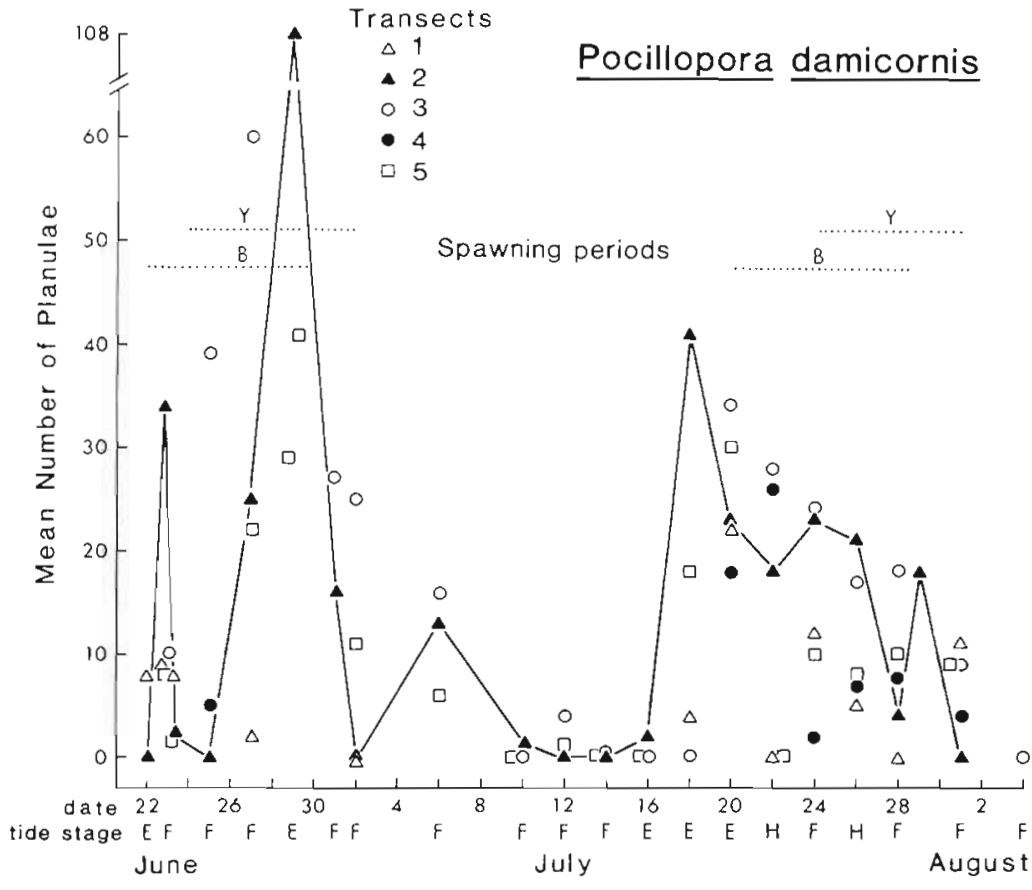

spawning in the laboratory and in the field on 26 July (Heyward in press). Eggs and planulae were subsequently recovered in numbers reaching 100 individuals $100 \mathrm{~m}^{-3}$ on the final $2 \mathrm{~d}$ of the study (Fig. 5).

The planulae of Cyphastrea ocellina were caught sporadically from all transects throughout the study period (Table 2). A maximum of 6 planulae $100 \mathrm{~m}^{-3}$ was recovered, too few to detect any peaks in abundance during the study.

Small numbers of Fungia scutaria larvae (Krupp 1983) were taken from all transects. If observations of

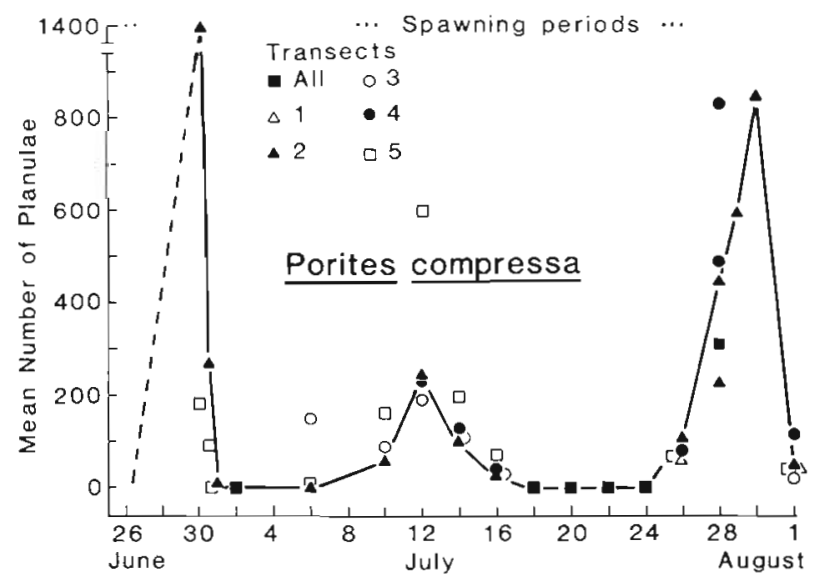

Fig. 4. Porites compressa. Daily mean number of planulae collected per $100 \mathrm{~m}^{3}$ seawater. Each data point represents mean catch from 3 tows along the specified transect. Solid line connects Transect 2 data points. Broken line indicates that numerous planulae were recovered on 27 and 29 June, but were not counted. The 3 short spawning periods are marked with dotted lines
F. scutaria spawning in the laboratory (Krupp pers. comm.) reflect spawning in the field, planulae were netted just after the June spawning and prior to the next spawning peak in July (Table 2). Because of their small size (Table 1), it is reasonable to assume that many F. scutaria larvae slipped through the $104 \mu \mathrm{m}$ mesh net.

A number of fast moving planulae (Fig. 6) which may belong to the sea anemone Cerianthus sp. were caught sporadically from all transects except the channel transect (Table 2). Similar larvae have been described by Carlgren (1906). Since settling experiments with these larvae failed, their identity has not been confirmed.

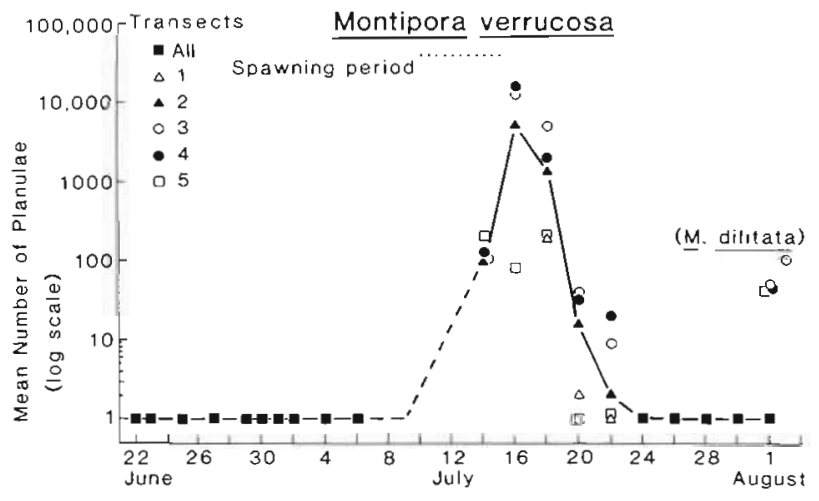

Fig. 5. Montipora verrucosa. Daily mean number of planulae collected per $100 \mathrm{~m}^{3}$ seawater (note log scale). Each data point represents mean catch from 3 tows along the specified transect. Broken line indicates that planulae were recovered but not counted on 11 and 12 July. Spawning period shown by dotted line 
Table 2. Abundance of Cyphastrea ocellina (Cy), Fungia scutaria (Fu) and Cerianthus-like (Ce) larvae $100 \mathrm{~m}^{-3}$. Each number is the combined total from 3 tows along the specified transect

\begin{tabular}{|c|c|c|c|c|c|}
\hline $\begin{array}{c}\text { Date } \\
\text { (in 1983) }\end{array}$ & $\begin{array}{c}1 \\
\text { Reef } \\
\text { flat }\end{array}$ & $\begin{array}{c}2 \\
\text { Reef } \\
\text { edge }\end{array}$ & $\begin{array}{c}\text { Transect } \\
3 \\
\text { Seaward } \\
10 \mathrm{~m}\end{array}$ & $\begin{array}{c}4 \\
\text { Seaward } \\
20 \mathrm{~m}\end{array}$ & $\begin{array}{c}5 \\
\text { Channel }\end{array}$ \\
\hline \multicolumn{6}{|l|}{22 Jun } \\
\hline 25 Jun & $10 \mathrm{Ce}$ & & & & \\
\hline 29 Jun & & $5 \mathrm{Fu}$ & & & \\
\hline $6 \mathrm{Jul}$ & & $2 \mathrm{Ce}$ & & & \\
\hline $10 \mathrm{Jul}$ & $1 \mathrm{Ce}$ & & & $1 \mathrm{Cy}$ & \\
\hline $14 \mathrm{Jul}$ & & & $6 \mathrm{Ce}$ & $2 \mathrm{Ce}$ & \\
\hline $18 \mathrm{Jul}$ & $2 C y$ & & & $2 \mathrm{Cy}$ & \\
\hline $20 \mathrm{Jul}$ & $2 \mathrm{Fu}$ & & & $2 \mathrm{Fu}$ & $2 \mathrm{Fu}$ \\
\hline $22 \mathrm{Jul}$ & & $3 \mathrm{Fu}$ & $4 \mathrm{Cy}$ & & \\
\hline $24 \mathrm{Jul}$ & $2 \mathrm{Cy}$ & $2 \mathrm{Cy}, \mathrm{Ce}$ & & $3 \mathrm{Fu}$ & \\
\hline $26 \mathrm{Jul}$ & & $2 \mathrm{Ce}$ & & & \\
\hline $28 \mathrm{Jul}$ & $2 \mathrm{Cy}, 4 \mathrm{Ce}$ & $2 \mathrm{Ce}$ & & & \\
\hline $29 \mathrm{Jul}$ & & $1 \mathrm{Cy}$ & & & \\
\hline
\end{tabular}

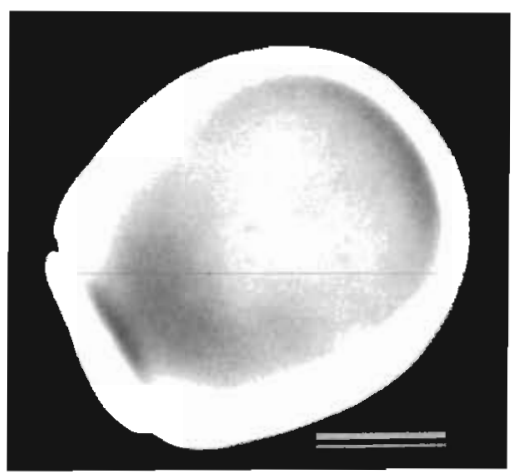

Fig. 6. Swimming Cerianthus-like larva, lateral view. Scale bar $=100 \mu \mathrm{m}$ See Table 1 for de. scription

Two types of zoanthid-like larvae were obtained in large numbers from tows along all transects. These larvae correspond to the 'zoanthina' type discovered by Semper (1867) and described in detail by Van Beneden (1890, 1898), Conklin (1908) and Cary (1911). They are essentially piriform, but have a latitudinal constriction located between their equator and oral end (Fig. 7). A ring of long $(100 \mu \mathrm{m})$ cilia which beat with a jerky motion in an anterior-posterior direction emanates from this circular groove.

Type 1 Semper's larvae were caught consistently throughout the study period and showed abundance peaks around 6 and 28 July (400 planulae $100 \mathrm{~m}^{-3}$; Fig. 8). Both Type 1 and 2 larvae were maintained in settlement jars for 2 wk periods, but none were induced to settle in the laboratory. Because of their abundance, it is likely that these larvae are derived from Palythoa vestitus and/or Zoanthus pacificus, the 2 most common zoanthids in Kaneohe Bay. Spawning of these species has not yet been observed directly (Cooke 1983).
Fig. 7. Type 1 Semper's larva, lateral view; flattened oral end to right. Central cilia are folded up due to fixation in formalin, thus appearing shortened. Scale bar $=100 \mu \mathrm{m}$. See Table 1 for description
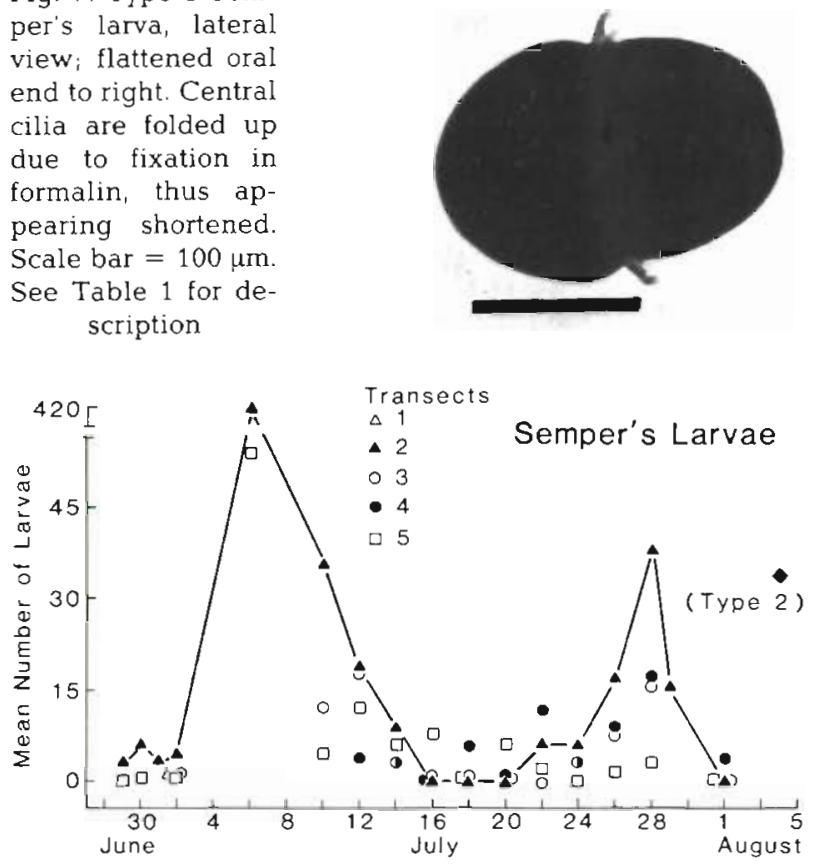

Fig. 8. Daily mean number of Semper's larvae collected per $100 \mathrm{~m}^{3}$ seawater. Each data point represents mean catch from 3 tows along the specified transect. Solid line connects Transect 2 data points. All data are for Type 1 Semper's larvae except on 4 August when Type 2 larvae were also collected (diamond)

An unidentified cnidarian planula (Fig. 9) was present throughout July and reached a peak of about 200 planulae $100 \mathrm{~m}^{-3}$ just prior to full moon. Despite repeated attempts using a variety of substrates, none of these larvae was induced to metamorphose in the laboratory, although several settled temporarily. Their abundance and color suggest that they may be the larvae of the common sea anemone, Anthopleura nig. rescens (Dunn 1974).

\section{Diurnal cycles}

Fig. $10 \& 11$ show the changes in abundance of Pocillopora damicornis planulae over a $24 \mathrm{~h}$ period (29 to 30 June), and of both $P$. damicornis and Porites

Fig. 9. Planula, possibly of Anthopleura nigrescens, a common sea anemone in Kaneohe Bay. Scale bar $=$ $100 \mu \mathrm{m}$. See Table 1 for description

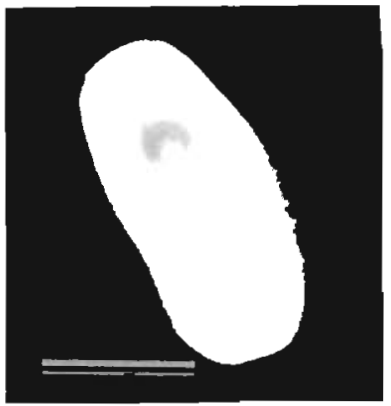




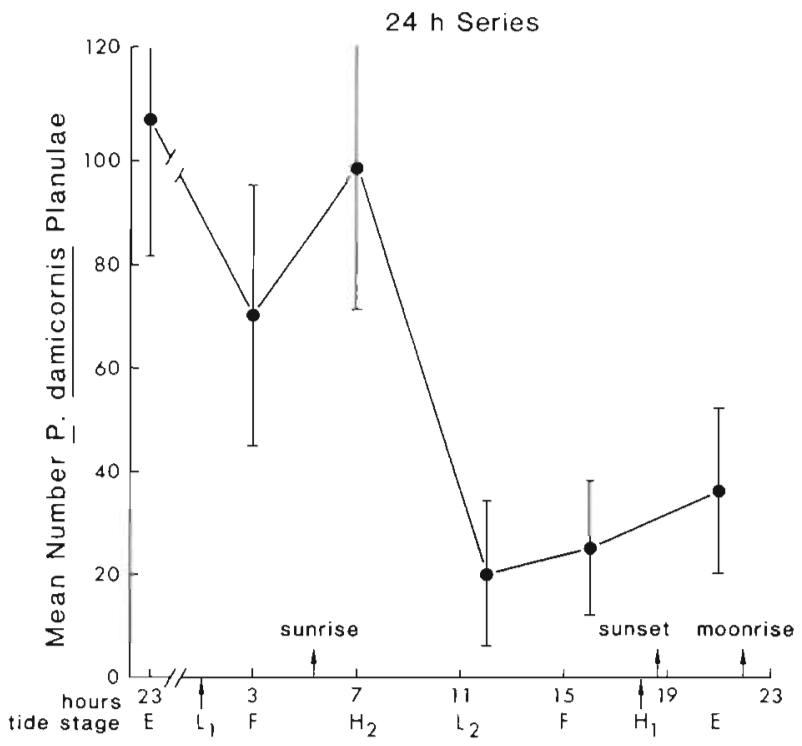

Fig. 10. Pocillopora damicornis. Mean number of planulae recovered per $100 \mathrm{~m}^{3}$ seawater, at $4 \mathrm{~h}$ intervals from $2300 \mathrm{~h}$ on 29 June to $2100 \mathrm{~h}$ on 30 June. Each data point is the mean of 4 double tows (up and back) along Transect 2. Error bars show 1 standard deviation. Tide stages: $\mathrm{E}=$ ebb (outgoing), $\mathrm{F}=$ flow (incoming), $\mathrm{L}=$ low $\mathrm{H}=$ high

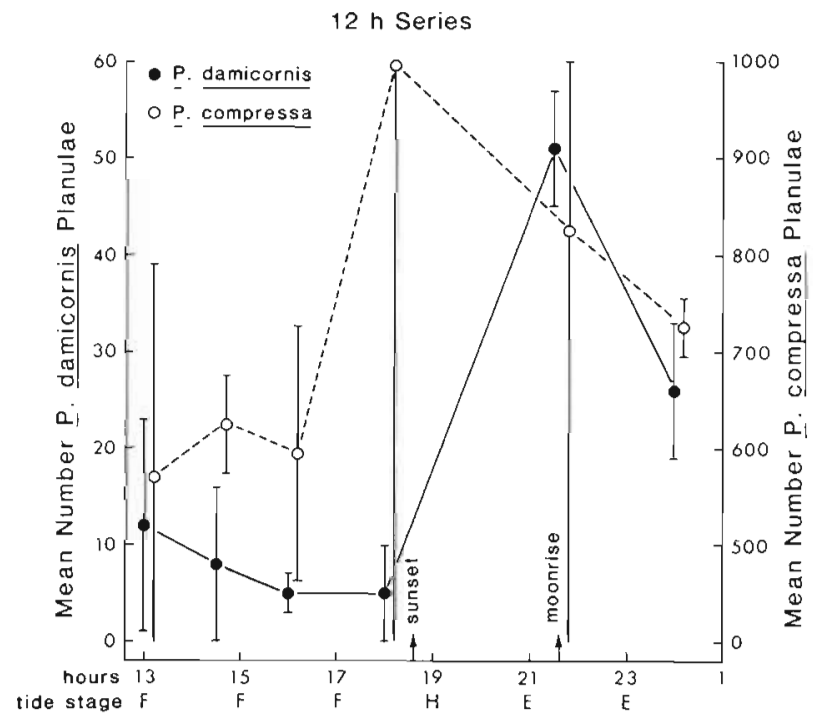

Fig. 11. Mean number of Porites compressa (broken line) and Pocillopora damicomis (solid line) planulae recovered per $100 \mathrm{~m}^{3}$ seawater, at $2 \mathrm{~h}$ intervals from $1300 \mathrm{~h}$ to $2400 \mathrm{~h}$, on 29 July. Each data point is the mean of 3 double tows (up and back) along Transect 2 . Error bars show 1 standard deviation. Tide stages: $E=$ ebb (outgoing), $F=$ flow (incoming), $\mathrm{H}=$ high

compressa planulae over a $12 \mathrm{~h}$ sampling period (29 July) along the seaward reef edge transect. There were significantly more $P$. damicornis planulae recovered from the night tows than from the day tows over the 24 $h$ period $(p<.001)$ and the $12 \mathrm{~h}$ period $(\mathrm{p}<0.025$; t-test,
Sokal \& Rohlf 1981). The mean abundance of $P$. compressa planulae captured during the night was not significantly different than the number caught during the day (12 h study). Peak abundance of P. damicornis planulae occurred at both high and low tides.

\section{Horizontal distribution}

On 11 out of 13 days when Pocillopora damicomis planulae were abundant, more planulae were recovered along Transect 3 than from each of the other transects (Fig. 3). The distribution of the other types of planulae among the 5 transects shows only a few consistent trends. The planulae of Montipora verrucosa were caught in greater numbers from Transect 4 than from the other transects (Fig. 5). In contrast, the Semper's larvae tended to be more common along Transects 1 and 2 than along Transects 3 and 4 .

\section{DISCUSSION}

\section{Problems with traditional procedures}

Perhaps the most common reason why coral planulae were rarely reported in previous tropical plankton studies is that many of these studies had a different focus. Coral planulae were simply overlooked or ignored. At best, they may have been relegated to a 'miscellaneous' category. However, this explanation cannot be applied to the studies wherein planulae were actively sought, but were found to be exceedingly rare or unobtainable (Yamaguchi 1972). In these cases, technical and biological factors may reconcile the low reported catch rate of planulae with the high fecundity of corals measured in the laboratory (Stimson 1978)

The results of the present study indicate that the problem may be linked to the traditional procedure of adding buffered formalin to plankton hauls as soon as possible' (UNESCO 1979). Formalin kills all of the plankton, which then settle to the bottom of the container; it has the secondary effect of bleaching the plankton. The various shades of brown that colored 9 out of the 12 larval types collected are due to brown endosymbiotic zooxanthellae. When the larvae are bleached or the zooxanthellae are expelled from them, the larvae are very difficult to see mixed in with the other bleached plankton. Formalin was also observed to disrupt the structural integrity of the delicate outer membrane of 1 and $2 \mathrm{~d}$ old Porites compressa and Montipora verrucosa planulae. Following routine handling (e.g. transfer of samples into storage jars) it was noted that many of these planulae had subse- 
quently fragmented. This makes identification difficult if not impossible. Formalin does not appear to damage the larger forms such as Pocillopora damicornis planulae in this manner. The 'cooling' procedure described above (see 'Materials and Methods'), provided a viable alternative to formalin fixation.

The above discussion can explain adequately why coral planulae have been reported so infrequently. Additional problems which, in the past, may have prevented the capture of planulae include: net mesh size too large, sampling at times when few corals were spawning or planulating, difficulties with identification, and as Kawaguti (1940a) suggested, insufficient amount of water filtered.

Although several coral species have been reported to planulate or spawn during every month of the year in various parts of the world, many species appear to concentrate their reproductive activities during summer (Stimson 1978, Fadlallah 1983, Harriot 1983, Harrison et al. 1984). Therefore plankton tows taken outside of this period would be less likely to contain planulae.

\section{Distribution of planulae}

Planulae share a common feature with most plankton in that they exhibit a highly patchy horizontal distribution (Balachandran 1973). Standard deviations were often as large as the mean in each set of 3 to 4 surface tows along a single transect, therefore they were not included in Fig. 3, 4, 5 \& 8. Tows taken minutes apart along the same transect show a disparity of thousands of planulae per $100 \mathrm{~m}^{3}$ of filtered seawater. One obvious cause of a patchy distribution of planulae in the plankton would be a patchy distribution of adult colonies on the reef. Spawning and planulation times of individuals of Montipora verrucosa and Pocillopora damicornis often differ by several hours (unpubl. own data), also contributing to patchiness. Numerous other potential biological and physical causes of plankton patchiness have been reviewed by Kimmerer (1980) and Parsons \& Takahashi (1973).

Despite plankton patchiness and complex water circulation patterns in the study area, spatial gradients in the abundance of Pocillopora damicornis, Montipora verrucosa and Semper's larvae were apparent. The gradients appear to reflect the abundance distribution of adult colonies of these species. The 2 zoanthid species are reef-flat inhabitants (Cooke 1983), and more Semper's larvae were recovered from Transects 1 and 2, over the reef, than from the other transects. $P$. damicornis colonies are most common on the outer reef flat of the study reef. The $P$. damicornis planulae were most abundant along Transects 2 and 3 , near the reef edge. Although $M$. verrucosa colonies are scattered across the study reef, the $M$. verrucosa larval abundance gradient increases away from the study reef. This gradient may be explained by the presence of a submerged ( 3 to $5 \mathrm{~m}$ deep) patch reef (about $250 \mathrm{~m}$ long $\times 150 \mathrm{~m}$ wide), located $125 \mathrm{~m}$ east of the study reef (Fig. 1). Brief qualitative surveys of this patch reef revealed the presence of numerous colonies of $M$. verrucosa and Porites compressa, but $P$. damicornis colonies were very rare.

An attempt was made to determine the potential of the patch reef as a source of planulae by comparing the planula abundance upwind with that downwind of the patch reef. On 20 July, during the spawning period of Montipora verrucosa, plankton tows were taken upwind of the patch reef in addition to sampling along the normal 5 transects. On this date, 10 times the number of $M$. verrucosa planulae and fertilized eggs were recovered from the downwind tows along Transects 3 and 4 than from those taken upwind, suggesting that the patch reef may be a large potential source of both Porites compressa and $M$. verrucosa planulae. In this area, living corals are restricted to the upper $10 \mathrm{~m}$ depth range. The muddy lagoon floor ( $15 \mathrm{~m}$ deep) is devoid of corals. There are no other possible sources of planulae in the vicinity.

Drogue and dye release experiments (Fig. 2b) indicate that, during tradewind conditions, some Montipora verrucosa and Porites compressa fertilized eggs/ planulae originating at the patch reef may be carried over the study reef by the southwest wind drift. Adult $P$. compressa colonies are abundant on both the patch reef and the study reef; this may account for the lack of a consistent larval abundance gradient among the transects for this species.

\section{Potential diurnal vertical migration}

Results of the 12 and 24 h sampling experiments indicate that more Pocillopora damicornis planulae are present at the surface at night than during the day (Fig. $10 \& 11)$. This information could suggest a nighttime spawning and planulation peak, and/or the possibility that the planulae of some species undertake diurnal vertical migration. In $24 \mathrm{~h}$ laboratory tests Harrigan (1972) and Holloran \& Witteman (in press) found that $P$. damicornis colonies may reach peak planulation at any time during day or night. In contrast, I observed Montipora verrucosa and $M$. dilitata colonies to spawn only at night, usually several hours after sunset (also see Heyward in press).

Kawaguti (1940b), gathered evidence which suggested vertical, diurnal migration of coral planulae in Iwayama Bay, Palau. Hodgson (in press) routinely recovered large numbers of Pocillopora damicornis 
planulae at $5 \mathrm{~m}$ depth in Kaneohe Bay during calm weather. Additional support for the idea of vertical migration comes from laboratory research on planula behavior. These studies have shown that the planulae of several species of coral respond to irradiance (Duerden 1902, Edmondson 1929, Abe 1937, Kawaguti 1941, Harrigan 1972, Lewis 1974), gravity and currents (Kawaguti 1941), and, because of their gregarious settling behavior, chemical and tactile stimuli (Duerden 1902, Edmondson 1929, Kawaguti 1941, Harrigan 1972, Lewis 1974). Planulae thus appear to have the ability to carry out a diurnal vertical migration.

The swimming rates of planulae of several coral species were measured by Atoda (1953) and Harrigan (1972). They are too slow (2 to $3 \mathrm{~mm} \mathrm{~s}^{-1}$ ) to allow a planula to make headway against the more rapid horizontal currents encountered over the study reef or in the bay (50 to $150 \mathrm{~mm} \mathrm{~s}^{-1}$ ). However, this swimming speed would allow for substantial vertical migrations of up to $11 \mathrm{~m} \mathrm{~h}^{-1}$.

\section{Potential export of coral planulae from Kaneohe Bay}

If large numbers of planulae are being produced in Kaneohe Bay, some may be exported out of the bay. Despite the huge dilution factors involved, planulae may be expected to be recovered up to several kilometers from a reef. Russell \& Colman (1934) and Harrison et al. (1984), netted coral planulae 5 and $2.5 \mathrm{~km}$ respectively from the nearest coral reef, in Australia. If the numbers of planulae exported from Kaneohe Bay are large in comparison to local planula production at, for example, the reefs just ouside of the bay entrance, the rate of coral recruitment on these reefs might be substantially increased by the 'extra' Kaneohe Bay planulae. In the general case, coral reef lagoons may be acting as planula production centers which enhance recruitment at locations outside the lagoons.

In order to estimate the number of coral planulae which may be exported from the southeast basin, it is necessary to know the average density of planulae in the water going out of the bay with the tide, and the daily gross outflow of water. The average abundance of all types of coral planulae from all transects combined per day during the study was 328 planulae $100 \mathrm{~m}^{-3}$. Several factors might affect the accuracy of applying this estimate to the entire southeast basin, especially the proximity of the plankton tow transects to potential sources of planulae. A conservative estimate of planula density for the upper $5 \mathrm{~m}$ of the southeast basin during the study, is considered to be on the order of 1 planula $100 \mathrm{~m}^{-3}$.

The average daily gross outflow of water from the southeast basin has been calculated to be approxi- mately $18 \times 10^{6} \mathrm{~m}^{3}$ (Bathen 1968). The majority of this water exits directly to the sea without passing via the north bay. About half of the gross outflow might not be expected to contain planulae if most planulae are concentrated above the $5 \mathrm{~m}$ depth range (Hodgson in press). Using the conservative estimate of planula density of 1 planula $100 \mathrm{~m}^{-3}$, and a gross outflow of planula-containing water of $9 \times 10^{6} \mathrm{~m}^{3} \mathrm{~d}^{-1}$, the average net export of planulae (assuming zero import) would be 90,000 planulae $\mathrm{d}^{-1}$. Over the $44 \mathrm{~d}$ study period this totals $4 \times 10^{6}$ planulae. Whether this number of exported planulae has a significant effect on recruitment at reefs outside the bay is unknown. The potential for the dispersal of coral larvae appears to be high.

\section{Planktonic lifespan of planulae}

It is tempting to infer a planktonic lifespan from the number of consecutive days a given planula type was recovered in plankton hauls. Most Pocillopora damicornis planulae were recovered in plankton tows within the $8 \mathrm{~d}$ planulation period observed in the laboratory (Fig. 3). Porites compressa and Montipora verrucosa planulae were recovered up to 6 and $7 \mathrm{~d}$ respectively after the last spawning observed in the field and laboratory (Fig. 4 \& 5).

Several studies of the settling behavior of planulae of several species of coral indicate that most planulae settle within a few days when provided a proper substrate (Vaughan 1908, Edmondson 1929, Abe 1937. Harrigan 1972, Lewis 1974). When deprived of a suitable settling site, e. g. improper substrate or insufficient irradiance, the majority of planulae tested survived several weeks without settling, and then successfully settled when an appropriate substrate was provided.

There are numerous potential factors other than settlement which could affect the number of consecutive days in which planulae of a given species were caught at the surface, especially export. The average residence time of the water in the southeast basin has been estimated to be $5 \mathrm{~d}$ (Bathen 1968), $4.5 \mathrm{~d}$ (Steinhilper 1970) and $13 \mathrm{~d}$ (Smith et al. 1981). Theoretically, this means that every planula released on Day 1, and not settled by the end of the residence time, will be exported out of the southeast basin. Other factors which could decrease the abundance of planulae near the surface are mortality due to predation or physical factors, and downward migration. More data is needed to confidently determine the planktonic lifespan of these coral planulae.

Acknowledgements. I thank all participants and staff of the summer course for encouragement and helpful advice, and 
the East-West Center for financial support. Special thanks go to Porfirio Aliño, Tom Clarke, Peter Glynn, Paul Jokiel, Susan Nakamura, Bob Richmond, John Stimson, Chris Stoddart, Lloyd Watarai and 4 anonymous reviewers. This paper is the result of the 1983, Hawaii Institute of Marine Biology 'Summer Program in Marine Science' sponsored by the Edwin W. Pauley Foundation, the University of Hawaii Foundation, and Sea Grant Program, Project No. F 238-F-582-B-315; under grant no. NA81AA-D-00070.

\section{LITERATURE CITED}

Abe, N. (1937). Postlarval development of the coral Fungia actiniformis var. palawensis Doderlein. Palao Trop. Biol. Stn Stud. 1 (1): 73-93

Alldredge, A. L., King, J. M. (1977). Distribution, abundance, and substrate preference of demersal reef zooplankton at Lizard Island Lagoon, Great Barrier Reef. Mar. Biol. 41: $317-333$

Atoda, K. (1953). The larva and postlarval development of the reef building coral. Sci. Rept. Tohoku Univ. 4 th. ser. (Biol.) 20 (1): 105-121

Bathen, K. H. (1968). A descriptive study of the physical oceanography of Kaneohe Bay, Oahu, Hawaii. Hawaii Inst. Mar. Biol. Tech. Rept. No. 14

Balachandran, T. (1973). Meroplanktonic stages of Anthozoa in the Indian Ocean. In: Zeitzschel, B. (ed.) The biology of the Indian Ocean. Springer-Verlag, New York, p. 289-292

Birkeland, C., Smalley, T. L. (1982). Comparison of demersal plankton from comparable substrata from a high island and an atoll. Proc. 4th Int. Coral Reef Symp., Manila 1: $437-442$

Bull, G. D. (1984). Planktonic dispersal of larval corals. Rept. to the Gr. Barrier Reef Mar. Park Authority, Townsville, Australia, July 1984

Bull, G. D. (in press). Distribution and abundance of coral plankton. Coral Reefs

Carlgren, O. V. (1906). Actinien larven 11 (3) Zoantherian larven Nordisches Plankton Zoologisches (6): 88-89. Reprinted by N. A. Asher, Amsterdam, 1964

Cary, L. R. (1911). Report upon investigations carried on at the Tortugas Laboratory during 1911. In: Cary, L. R., (ed.) Rearing of Zoanthella. Carnegie Instn Wash. Yearbook 10: 142

Clutter, R. I. (1973). Plankton ecology. In: Cox, D. C., Gordon, L. C., (ed.) Estuarine pollution in the State of Hawaii, Part 2, Kaneohe Bay study. University of Hawaii Water Resources Center Tech. Rept. No. 31. p. 185-213

Conklin, E. G. (1908). Two peculiar actinian larvae from Tortugas, Florida. Papers from the mar, biol. lab. Tortugas Carnegie Instn Wash., D. C. 2: 173-186

Cooke, W. J. (1983). The ecology of Palythoa vestitus and Zoanthus pacificus (Zoanthidea, Anthozoa) in Kaneohe Bay, Oahu, Hawaii. Ph. D. dissertation, University of Hawaii

Duerden, J. E. (1902). West Indian madreporarian polyps Mem. natn. Acad. Sci. 8: 402-597

Dunn, D. F. (1974). Redescription of Anthopleura nigrescens (Coelenterata, Actinaria) from Hawaii. Pacif. Sci. 28 (4): $377-382$

Edmondson, C. H. (1929). Growth of Hawaiian corals. Occ. Pap. Bernice P. Bishop Museum, Bull. No. 58

Fadlallah, Y H. (1983). Sexual reproduction, development and larval biology in scleractinian corals. Coral Reefs 2: $129-150$

Fraser, J. H. (1979). The history of plankton sampling. In:
Tranter, D. J. (ed.) Zooplankton sampling, Pt. I. Reviews on zooplankton sampling. Unesco, Paris, p. 11-18

Harrigan, J. F. (1972). The planula larva of Pocillopora damicornis: Lunar periodicity of swarming and substratum selection behavior. Ph. D. dissertion, Dept. of Zoology, University of Hawaii

Harriot, V J. (1983). Reproductive ecology of four scleractinian species at Lizard Island, Great Barrier Reef. Coral Reefs 2: 9-18

Harrison, P. L., Babock, R. C., Bull, G. D., Oliver, J. K. Wallace, C. C., Willis, B. L. (1984). Mass spawning in tropical reef corals. Science 223 (4641): 1186-1189

Highsmith, R. C. (1982). Reproduction by fragmentation in corals. Mar. Ecol. Prog. Ser, 7: 207-226

Heyward, A. (in press). Sexual reproduction in five species of the coral Montipora. In: Jokiel, P. L., Richmond, R. H. (ed.) Coral reef population biology. Hawaii Inst. Mar. Biol. Tech. Rept.

Hodgson, G. (in press). The vertical distribution of planktonic coral larvae in Kaneohe Bay, Oahu, Hawaii. Proc. 5th Int. Coral Reef Congress, Papeete, 1985

Holloran, M. K., Witteman, G. J. (in press). Diurnal and monthly variation in planula production in the reef coral Pocillopora damicornis. In: Jokiel, P. L., Richmond, R. H., (ed.) Coral reef population biology. Hawaii Inst. Mar. Biol. Tech. Rept.

Kawaguti, S. (1940a). An abundance of reef-coral planulae in plankton. Dobutsugaku Zasshi (Zoological Magazine, Tokyo) 52 (1): 31

Kawaguti, S. (1940b). Miscellaneous data obtained in the study of reef corals. Kagaku-Nanyo 2 (3): 159-169. (In Japanese)

Kawaguti, S. (1941). On the physiology of reef corals. 5. Tropisms of coral planulae, considered as a factor of distribution of the reefs. Palao Trop. Biol. Stn Stud. 2 (2): 319-328

Kimmerer, W. J. (1980). Plankton patchiness and ecosystem stability. Ph. D. dissertation. Dept. of Oceanography, University of Hawaii

Krupp, D. (1983). Sexual reproduction and early development of the solitary coral Fungia scutaria (Anthozoa: Scleractinia). Coral Reefs 2: 159-164

Lewis, J. B. (1974). The settlement behavior of planula larvae of the hermatypic coral Favia fragum (Esper). J. exp. mar. Biol. Ecol. 15: 165-172

Parsons, I R., Takahashi, M. (1973). Biological oceanographic processes. Pergamon Press, Elmsford, New York

Porter, J. W., Porter, K. G. (1977). Quantitative sampling of demersal plankton migrating from different coral reef substrates. Limnol. Oceanogr. 22 (3): 553-556

Porter, J. W., Porter, K. G., Batac-Catalan, Z. (1977). Quantitative analysis of Indo-Pacific demersal reef plankton. Proc. 3rd. Int. Coral Reef Symp. 1: 105-110

Richmond, R. H. (1982). Energetic considerations in the dispersal of Pocillopora damicornis (Linnaeus) planulae. Proc. 4th Int. Coral Reef Symp. 2: 153-156

Richmond, R. H., Jokiel, P. L. (1984). Lunar periodicity in larval release in the reef coral Pocillopora damicornis at Enewetak and Hawaii. Bull. mar Sci. 34 (2): 280-287

Russell, F. S., Colman, J. S. (1934). The zooplankton. II. The composition of the zooplankton of the Great Barrier Reef lagoon. Scient. Rep. Gt Barrier Reef Exped. 1928-29. 2 (6): 159-174

Semper, D. V. (1867). Uber einige tropische Larvenformen. Zeit. Wiss. Zool. 17: 413

Semper, K. G. (1881). Animal life as affected by the natural conditions of existence. D. Appleton, New York 
Smith, S. V., Kimmerer, W. J., Laws, E. A., Brock, R. E., Walsh, T. W. (1981). Kaneohe Bay sewage diversion experiment: perspectives on ecosystem responses to nutritional perturbation. Pacif. Sci. 35 (4) : 279-402

Sokal, R. R., Rohlf, F. J. (1981). Biometry. W. H. Freeman, San Francisco

Steinhilper, F. A. (1970). Particulate organic matter in Kaneohe Bay, Oahu, Hawaii. Hawaii Inst. of Mar. Biol. Tech. Rept. No. 22. University of Hawaii

Stephenson, T. A. (1931). Development and the formation of colonies in Pocillopora and Porites. Pt. I. Sci. Rept. Great Barrier Reef Exped. 1928-29. 3: 113-134

Stimson, J. S. (1978). Mode and timing of reproduction in some common hermatypic corals of Hawaii and Enewetak. Mar. Biol. 48: 173-184

UNESCO (1979). Smaller mesoplankton. Report of working party No. 2. Pt. 2. Standardization of zooplankton sampling methods at sea. In: Fraser, J. H. (ed.) Zooplankton sampling. Unesco, Paris

Van Beneden, E. (1890). Les anthozaires pelagiques recuilles par le professeur Hensen, dans son expedition du plancton. I. Une larve voisine de la larva de Semper. Arch. de Biol. 10: 485-522
Van Beneden, E. (1898). Les anthozoaires de la PlanktonExpedition. Res. de la Plankton Expediton d. HumboldtStiftung. 2

Vandermeulen, J. H. (1974). Studies on reef corals. II. Fine structure of planktonic coral larva of Pocillopora damicornis, with emphasis on the aboral epidermis. Mar. Biol. 27 : 239-249

Vaughan, T W. (1907). Recent Madreporaria of the Hawaiian Islands and Laysan. Smithsonian Inst. Bull. 59

Vaughan, T. W. (1908). Geology of the Florida Keys and the marine bottom deposits and recent corals of Southern Florida. Carnegie Instn. Wash. Yearbook 7: 135-136

Vaughan, T. W. (1910). The recent Madreporaria of southern Florida. Carnegie Instn. Wash. Yearbook 9: 135-144

Walter, C., Talaue, L., Pasamonte, J. N. (1982). A preliminary study on emergence of reef associated zooplankton from a Philippine coral reef. Proc. 4th. Int. Coral Reef Symp., Manila 1: 443-451

Yamaguchi, M. (1972). Preliminary report on a plankton survey in Palau, December 1971 to January 1972. Univ. Guam Mar. Lab. Tech. Rept. No. 5

This paper was presented by Professor C. Birkeland; it was accepted for printing on June 5, 1985 